\title{
La Responsabilidad Social Corporativa
} implica un Nuevo Modelo de Gestión

Corporate Social Responsibility involves a New Management Model

Mg. Lourdes Paola Ortiz Arturo Universidad Tecnológica Israel portiz@uisrael.edu.ec

Fecha de recepción: 03/09/2014 Fecha de aceptación: 04/10/2014

Resumen

La responsabilidad social de las empresas es una idea que se ha posicionado en las diferentes capas de la sociedad. Las escuelas de negocios han desarrollado, dedicado al estudio y la promoción de centros de responsabilidad social. Esto demuestra que el concepto de responsabilidad social tiene que ser desarrollado en cualquier empresa como modelo de negocio. Con este artículo, tengo la intención de generar una cultura de la responsabilidad social de la empresa para asegurarse de que es un bien común para todos los interesados.

Palabras claves: Integrantes de Responsabilidad Social, Voluntariado, Sustentabilidad, Cogobierno, Sostenibilidad. 


\section{Introducción}

En los últimos tiempos, se ha reclamado con razón a las empresas que colaboren más positivamente a paliar las injustas condiciones en la distribución de la riqueza y otros problemas del contexto social, problemas que muentender a la empres 作 rentabilidad económica. Tal vez podmos entences suponer que estamos en co comienzo de una recuperación de la que dan muestras varias instituciones, movimientos e inquietudes. Establecer una empresa responsable ante la sociedad implica toda una actitud ante el sentido del trabajo
y de la vida de la sociedad por parte de quienes conforman la empresa. Este cambio en la mirada se hace más necesario si tenemos en cuenta la importancia que tiene la temática de la Responsabilidad Social Emmás necesario si tenemos en cuenta la importancia que tiene la temática de la Responsabilidad Social Empresarial especialmente en Latinoamérica y en países emergentes en general. El contexto latinoamericano nos presenta problemas, tanto en el ámbito económico como el político y en lo social, que nos hablan de la sostenido en la región.

Para ayudar a resolver este vacío y la sensación de falta de rumbo, las políticas de Responsabilidad Social Empresarial que llevan adelante las empresas son una gran oportunidad para mostrar caminos creativos e innovadores que sumen a los diferentes actores sociales, incluidos los gobiernos; para comenzar un proceso de novadores que sumen a los diferentes actores sociales, incluidos los gobiernos; para comenzar un proceso de cambio que redunde en una sociedad más equitativa y justa. La empresa moderna debe involucrarse y atender a las nuevas expectativas y exigencias, no solo cuando se dirige a sus clientes, sino tambien en las relaciones con
sus propios recursos humanos y el resto de la sociedad. Así, cobra cada día más importancia la responsabilidad social de la empresa, su implicación con la comunidad y su aporte a la solución de los problemas que interesan a la ciudadanía. Para abordar esta nueva realidad, es necesario que la empresa implemente un Programa de Responsabilidad Social Corporativa.

Un programa de esta índole tiene como objetivo contribuir al desarrollo de la comunidad de que la empresa es parte. De esta forma, la organización responde al nuevo concepto de empresa que demanda la sociedad, según el cual las organizaciones comerciales no solo deben preocuparse por la rentabilidad, sino también por el desarrollo y bienestar de la comunidad con la que están vinculadas.

El reto que enfrenta la empresa moderna es monumental. Su objetivo no se limita a obtener reconocimiento del mercado, sino que ahora es mucho más amplio. Apunta al reconocimiento de la sociedad por el cumplimiento de su compromiso con esta, además de una aceitada relación con los clientes y una preocupación por la capacitación y el bienestar de sus recursos humanos. La empresa actual sabe que necesita legitimación por parte de la sociedad; esto implica, además de responder a los requerimientos del mercado, comprender el medio donde actúa y estar atenta ante las nuevas demandas sociales. Para ello le es preciso replantear constantemente su razón de ser, misión y principios, y revisar su conducta empresarial en el día a día. Se trata de un objetivo 
múltiple que se extiende a lo económico, lo social y la conservación del medio ambiente. La Responsabilidad Social Corporativa es un nuevo modelo de gestión que posibilite a la empresa obtener ventajas competitivas, innovar y anticiparse a la competencia.

Ante la estandarización global de la oferta, la Responsabilidad Social Corporativa puede contribuir en forma

\section{Desarrollo}

La Responsabilidad Social Coporativa favorece las inversiones y eleva el valor de la empresa. Genera oportunidades comerciales y ventajas competitivas, contribuye al desarrollo sostenible, alienta "la relación con
los stakeholders, crea sentido de pertenencia y retiene recursos humanos talentosos, consolida la cultura corporativa y mejora el clima laboral, constituye un factor clave de liderazgo empresarial, promueve la imagen ventajas. (Aguero, 2002).

La Responsabilidad Social Corporativa debe ser gestionada como cualquier otra área comercial, de recursos humanos o de producción, la Responsabilidad Social Corporativa también ha de ser planificada y gestionad en forma sistematica y profesional.

Entre los cambios experimentados por la sociedad en los últimos años, se destacan la creciente importancia adquirida por los valores sociales y el compromiso de los individuos con diferentes causas y organizaciones en el ámbito del llamado Tercer Sector. Los empresarios deben liderar este cambio, ser sensibles a las demandas del entorno y crear las condiciones necesarias para que el desarrollo pleno de talento de la empresa le permita a ésta obtener ventajas competitivas y conseguir sus propósitos.

Un liderazgo ético y social es el que utiliza la reputación, el compromiso, la visión a largo plazo y una actuación impecable en lo ético y lo social, para promover el desarrollo de una empresa socialmente responsable.

\section{Una visión de Responsabilidad Social Corporativa}

De la investigación realizada se desprende la noción de que si bien existe un amplio consenso sobre alguno aspectos que caracterizan el concepto, también ha de constatarse que las definiciones que la literatura propone son relativamente amplias y vagas. Uno de los probables motivos por los cuales la noción de Responsabilidad Social Corporativa no goza de una precisa definición, es la relativa novedad del tema, tanto a nivel de las experiencias empresariales como de la reflexión en la materia. Es preciso agregar que puede dificultar la elaboración de una definición, el hecho que la Responsabilidad Social Corporativa aborda una multiplicidad de ámbitos: bienestar de los trabajadores, igualdad en los procesos de selección del personal, conflicto de intede ámbitos. bienestar de los trabajacte conficto de inteahorro de energía, competencia, relaciones con la comunidad, etcétera.

\section{Algunas definiciones}

Kotler y Armstrong (Principios de Marketing) "El marketing social parte del presupuesto del que la organización debe determinar la necesidad, deseos de mantener o mejorar el bienestar del cliente y la empresa". (Kotler 2003)

Dickson (Marketing. Las mejores prácticas)

"Responsabilidad Social es un conjunto de filosofías, políticas, procedimientos y acciones de marketing con la intención primordial de mejorar el bienestar social". (Dickson, 1993)

\section{Friedrich \& Ferrer}

"Ser socialmente responsable implica maximizar los efectos positivos sobre los "stakeholders" y minimizar los efectos negativos de sus acciones en la comunidad". (Ferrer, 2009)

\section{Según las Naciones Unidas (ONU):}

"Optemos por el poder de los mercados con la autoridad de los ideales universales. Optemos por conciliar las fuerzas creativas del espíritu de la empresa privada con las necesidades de los desfavorecidos y de las generaciones futuras". Kofi Annan, Secretario General de las Naciones Unidas.

\section{Según la Organización para la Cooperación y el Desarrollo Económico (OCDE)}

Las líneas directrices forman parte de la "Declaración de la OCDE sobre inversión internacional y de empresas multinacionales". Un conjunto de recomendaciones dirigidas por los gobiernos de la OCDE a as empresas multinacionales. Fueron adoptadas en 1999.

El objetivo de las líneas directrices es "garantizar que las empresas multinacionales lleven a cabo sus actividades sin entrar en conflicto con las políticas públicas locales, fortalecer la base de confianza mutua entre las empresas y las sociedades donde desarrollan su actividad, contribuir a mejorar el clima para la inversión extranjera y potenciar la contribución de las empresas multinacionales al desarrollo sostenible".

Las empresas deberán tener plenamente en cuenta las políticas fijadas por los países en que ejercen su actividad y tener en consideración las opiniones de los demás terceros interesados. 
A este respecto, las empresas deberán:

- Contribuir al progreso económico, social y medioambiental con vistas a lograr un desarrollo sostenible. Respetar los derechos humanos de las personas afectadas por sus actividades de conformidad con las obligaciones y compromisos internacionales del gobierno de acogida.

- Estimular la generación de capacidades locales mediante una cooperación estrecha con la comunidad local, - Es los merca saludables.

- Fomentar la formación del capital humano, particularmente mediante la creación de oportunidades de empleo y el ofrecimiento de formación a los empleados.

- Abstenerse de buscar o de aceptar exenciones no contempladas en el marco legal o reglamentario relacionadas con el medio ambiente, la salud, la seguridad e higiene, el trabajo, la fiscalidad, los incentivo financieros u otras cuestiones varias.

- Apoyar y defender unos correctos principios de gobierno empresarial, desarrollar y aplicar unas buenas prácticas de gobierno empresarial.

- Desarrollar y aplicar prácticas auto disciplinarias y sistemas de gestión eficaces que promuevan una relación de confianza recíproca entre las empresas y las sociedades en las que ejercen su actividad.

Promover el conocimiento por los empleados de las políticas empresariales y su conformidad con ellas, mediante una difusión adecuada de las mismas, incluso a través de programas de información.

- Abstenerse de tomar medidas discriminatorias o disciplinarias contra los trabajadores que elaboren, de buena fe, informes para la dirección o, en su caso, para las autoridades públicas competentes acerca de las prácticas contrarias a la ley, a las directrices o a las políticas de la empresa.

- Alentar, cuando sea factible, a los socios empresariales, incluidos proveedores y subcontratistas, para que apliquen principios de conducta empresarial compatibles con las directrices. Abstenerse de cualquier injerencia indebida en actividades políticas locales.

Según la Comisión de las Comunidades Europeas:

La mayoría de las definiciones de la responsabilidad social de las empresas entienden este concepto como la integración voluntaria, por parte de las empresas, de las preocupaciones sociales y medioambentales en sus operaciones comerciales y sus relaciones con sus interlocutores.
Según la Fundación Ecología y Desarrollo (ECODES)

La adopción de criterios de Responsabilidad Social Corporativa (RSC) en la gestión empresarial entraña:

La formalización de políticas y sistemas de gestión en los ámbitos económico, social y medioambiental, la transparencia informativa respecto de los resultados alcanzados en tales ámbitos y el escrutinio externo de

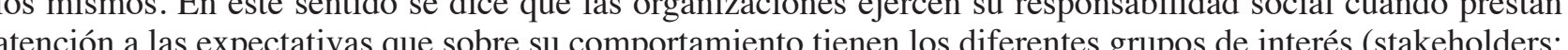
empleados, socios, clientes, comuidades locales, medioambiente, accionistas, proveedores, etc.), con el propósito último de contribuir a un desarrollo social y ambientalmente sostenible y económicamente viable.

\section{Según el Banco Mundial:}

Una empresa sostenible es aquella que crea valor económico, medioambiental y social a corto y largo plazo; contribuyendo de esa forma al aumento del bienestar y el auténtico progreso de las generaciones presentes y futuras, tanto en su entorno inmediato como en el planeta en general.

\section{Nociones de Responsabilidad Social Corporativa y Filantropía}

¿El concepto de Filantropía puede asimilarse al que se refiere a la Responsabilidad Social Corporativa? o más bien ¿es un elemento de dicha responsabilidad? A continuación propongo una reflexión sobre la posible diferenciación entre ambos conceptos:

Nada dice en el término de Filantropía que se trata de una actitud corporativa; de hecho, como lo indican varios autores, tradicionalmente la filantropía ha sido el hecho de empresarios, no decisiones tomadas a nivel corporativo.

La Responsabilidad Social Corporativa implica una política empresarial comprometida en el tiempo. Es una forma de acción social duradera. Por otra parte, la Filantropía no requiere la existencia de ningún tipo de política a mediano o largo plazo. Lo que diferencia fundamentalmente los dos conceptos se centra en la presencia de necesarias conexiones entre la Responsabilidad Social Corporativa y la organización inter y externa de la empresa. Estas conexiones no condicionan la acción filantrópica. Una empresa no necesita modificar su propia organización para emprender acciones filantrópicas.

La Filantropía se caracteriza por ser una acción gratuita. Esta no persigue ningún interés para su autor; en cambio, la Responsabilidad Social Corporativa sí busca el mejoramiento del entorno interno y externo de la empresa con fines estratégicos: fidelizar al cliente, mejorar la imagen de la empresa, mejorar la competitividad de la empresa, adaptar la administración empresarial a nuevos contextos, etc.

Sin embargo, debemos también observar que la Filantropía puede revestir una amplia gama de formas entre las cuales podemos distinguir la asistencia, la beneficencia y otras formas. Vale entonces preguntarse si y en 
qué condiciones la empresa que sistemáticamente recurre a la Filantropía no asume una forma de Responsabilidad Social.

\section{Evolución de la sensibilidad social en torno a temas éticos}

"Las creencias del público han evolucionado, sin lugar a duda, durante la segunda parte del siglo XX hacia temas éticos. ¿Quién hoy en día no comparte la idea que hay que reforzar la ética pública (probidad administrativa, gestión pública transprente, derecho a la información pública, etcétera), la ética en la información (información veraz, rechazo del sensaciona lismo, propiedad de los medios de comunicación socinormación en los negocio" (Berti 2008). Sobre las causas der crecimiento de negocios, destaco los siguientes factores:

\section{Aumento de la Educación}

Este fenómeno influye indudablemente sobre la preferencia del público para los productos con alto valor agregado cultural y la facultad del consumidor de comparar los productos entre ellos para elegir el que responde los criterios culturales deseados. Ha de constatarse que "la competencia y el desarrollo tecnológico, hace que los costos de los productos y servicios bajen a niveles similares". Como consecuencia de lo anterior, el precio del producto no es el principal elemento de la demanda. (Caravedo, 1998) Además, la educación ha permitido a quienes trabajan en una empresa un mejor conocimiento de los derechos laborales y de los instrumentos para obligar al respeto de estos.

Mejor y Mayor representación de la ciudadanía: es cierto que existen en la actualidad varias organizaciones civiles que se dedican a la defensa de los ciudadanos. Ellos recurren a la acción no violenta (Greenpeace, los sindicatos), a la denuncia (Amnesty International), la representación en justicia (Asociaciones de consumidores, sindicatos) o a otras formas para el respeto de los valores que ella valoriza. Mayor acceso a la información "La Sociedad del fin del siglo XX se ha caracterizado por el desarrollo de la tecnología de la información" (Cedice, 2008). Las noticias llegan no solamente con gran velocidad de todas partes del mundo pero el espectador "presencia" (a través de las imágenes que le llegan) los efectos catastróficos de las noticias (accidentes petroleros y la polución, despidos masivos y protestas, condiciones de trabajo y salud de los trabajadores, etc.).

Evolución de las regulaciones en materias sociales, económicas, penales, etc.

Una de las tendencias del Derecho moderno es su mayor pretensión de proteger a los actores sociales en situaciones de inferioridad (el caso del trabajador y consumidor frente al poder de la empresa), a defende valores (lucha contra la corrupción, protección del medio ambiente y derechos humanos), y a intervenir en la regulación de los mercados (prácticas desleales). Hay que resaltar que esta evolución ha sido, entre otros, la consecuencia de numerosos compromisos contraídos en el marco de Organizaciones Internacional y Regionales. "De ahí que las regulaciones nacionales en materia medioambiental, laboral, sanitaria, financiera conales. Détera por una pa impone conterega de a los delincestes (multa me time y medioambientales). (Fuentes, 2007).

\section{¿Aparición de una nueva generación de empresas?}

Frente a estos cambios el actuar de la empresa ha cambiado también, fruto de varios factores:

El empresario, a la vez hombre de negocio y ciudadano, es más sensible a los valores éticos defendidos por la sociedad.

"La estructura del comercio ha evolucionado. El comercio dejó de estar fundamentalmente centrado en las transacciones de bienes y presenta un importante volumen de comercio de servicios." (Victor, 2010).

Hoy en día, el comercio de servicios representa un $60 \%$ del comercio de los países desarrollados.

Es un mercado muy competitivo, la empresa debe seducir a la clientela con "argumentos" atractivos. El comportamiento responsable de la empresa es uno (quizás el más importante) de estos argumentos. De este modo, la compañía moderna presenta una imagen limpia al público, lo que procura posibles beneficios a la empresa que recurre a una política de Marketing con Causa. La definición de Marketing con Causa es una actividad de carácter planificado y proactivo emprendida por las empresas como consecuencia de una orientación hacia la responsabilidad social y de sus políticas de marketing. La empresa que no se adapta a este nuevo mercado puede perder mucha competitividad.

Las prácticas responsables disminuyen los trámites y demoras administrativas, los litigios y sus costos. La empresa busca hacer negocios en un contexto favorable a los negocios: esto lo puede garantizar un ambiente social donde existe estabilidad, ética, educación y desarrollo.

\section{Ética en la Responsabilidad Social Corporativa}

Definir términos que tienen una larga historia no es tarea fácil, porque a lo largo de los siglos los usuarios los han ido enriqueciendo con matices diferentes, y querer encerrarlos todos tras las rejas de una definición resulta imposible.

La ética es un tipo de saber de los que pretende orientar la acción humana a un sentimiento racional. La ética de la empresa es, en este sentido, una parte de la ética aplicada, como lo es toda ética de las organizaciones y de las profesiones, y tiene que reflexionar sobre cómo aplicar los principios mencionados a la actividad empresarial. 
"Sin embargo, esto no basta, porque la aplicación no puede consistir simplemente en tomar unos principios geneales y aplicarlos en todos los campo, como si cada uno de ellos no tuviera su especificider. Comosi ha enpresarial fuera igual que la sanitaria o la docente, y ninguna de ellas aportara por si misma ningún tipo de exigencias morales y valores morales." (IRSE, 2009). Por eso la tarea, de la ética aplicada no consiste solo en la aplicación de los principios generales, sino en averiguar (a) sociedad, qué

Por último, también una ética aplicada a las organizaciones tiene que tener en cuenta la moral cívica de la sociedad en la que se desarrolla, y que ya reconoce determinados valores y derechos como compertidos por ella. Una cultura organizacional basada en pilares éticos robustos y valores fundamentales como la igualdad y el respeto, puede influir positivamente en el desempeño de la empresa. La cuestión ética es de gran relevanci para todo individuo y se extiende al ámbito empresarial. En cada decisión que se tome, estará inmiscuido algo para todo individuo y se extiende al ámbito empresarial. En cada decisión que se tome, estará inmiscuido algo dos, de asignación de responsabilidades o de lanzar una promoción, la ética siempre está presente.

Actualmente, cuando existen más organizaciones que pugnan por la transparencia y con la Internet como herramien-

"Sin valores sólidos estamos coqueteando con el desastre. Con valores sólidos, podemos enfrentar a los mercados internacionales," (Montero, 2007).

Sin duda, hay quienes ponen por encima de los valores y la ética los resultados financieros, pero no se dan cuenta que la ética corporativa puede ser una fuente de ventajas competitivas, ya que por medio de ella se pueden atraer clientes y personal de primer nivel.

A través de la ética se puede acabar con prácticas corruptas que destruyen valor y dañan la economía y la sociedad, si ponderamos más la cultura organizacional, con valores comunes (más que código o reglas) que sirvan como sendero de los individuos que conforman las organizaciones podríamos dar mayores componentes éticos a una empresa.

"Si nos basamos en que el capital humano es uno de los mayores activos empresariales, si no el mayor, tomamos conciencia que estas personas valen por sí mismas, que se les debe respetar y que no se les puede tratar como un medio sino como un fin, habremos dado el primer paso para fundamentar éticamente las instituciones (1993).

Una organización que viva según los cinco valores básicos: igualdad, libertad, diálogo, respeto y solidaridad estará mejor preparada para el futuro. Estamos viviendo tiempos de globalización que han hecho que las organizaciones sean más planas, más descentralizadas y con empleados más autónomos y con mayor poder de decisión, por esto se hace necesario que las relaciones no sólo al interior de las empresas sino entre empresas y demás organizaciones, se basen en los cinco valores arriba mencionados, lo cual generará mejores patrones de conducta y permitirá generar valor.

\section{Los componentes de una empresa ética:}

Aunque pueden ser innumerables, los siguientes darían lugar a las bases de una ética organizacional:

1. Vivir de acuerdo con los cinco valores fundamentales.

2. Una cultura organizacional con valores comunes para sus miembros.

3. Luchar por alcanzar la satisfacción de todos los agentes involucrados en la empresa: accionistas, directivos, empleados, proveedores y clientes.

4. Asumir la responsabilidad social por sus actuaciones.

5. Pesa más el contrato moral entre la empresa y sus integrantes y asociados que el mero contrato legal.

Cuando se logran incorporar estos componentes básicos se llega a generar mayor valor económico, ya que las relaciones, no solo laborales, sino entre proveedor y empresa, cliente y empresa, etc. mejorarán y el tiempo y los recursos que se invertía en mejorar las ineficiencias que se presentaban en dichas relaciones, podrá ser invertido en aquellos aspectos que lo demanden.

"La ética suele mejorar el funcionamiento de la empresa mediante varias vías:

Reduce los conflictos de los miembros que la forman. Mejora la imagen exterior de sí misma.” (Puterman)

\section{La Ética en la Administración}

Muchas veces, en el intento de vincular la ética al contexto de la administración, observamos en la práctica, estos dos conceptos muy difíciles de unir, puesto que lo que uno implica, puede ser utilizado en contraposición a la aplicación del otro. Desafortunadamente, gran cantidad de administradores, manejan una ideología tan lineal en su visión y el ejercicio de su profesión, que no permiten involucrarse más allá en lo tocante a las funciones que le son adjudicadas.

Teniendo ya diferenciado el concepto de la ética, analizamos que cientos de veces, los criterios que maneja un administrador, tales como la eficiencia, la eficacia, la productividad, y la rentabilidad, se quedan muy cortos en 
cuanto a la comprensión de este término, puesto que en la mayoría de los casos, sólo propenden por desarrollar el pequeño núcleo o negocio en el cual participa, sin tener en cuenta un contexto mucho más amplio en el que se hallan inmersos.

Ya existe bastante literatura sobre la importancia de actuar bajo la filosofía del pensamiento sistémico. Para entenderla es indispensable concer que dentro de un movimiento circular funcionan cientos de pasos como entenderla es indispensable conocer que dentro de an movimiento circular, funcionan cientos de pas como

Pese a la gran teorización que existe sobre el tema, y la difusión que ya se está dando sobre el mismo, son mu pocas las personas de un cargo determinado, sino en su vida misma.

Cuando se habla de la ética, comprendida dentro de una ideología sistémica, se entiende por ejemplo la importancia de preservar la ecología, cuestión muchas veces entendida en función inversa a la de la rentabilidad. Pero cuando se mira desde otra perspectiva, se llega a deducir que un daño al ecosistema no sólo se transmite en el pago de una multa, bajo la premisa según la cual "el que contamina, paga", sino que a la larga va a revertirse en costos más altos para la empresa, ya que a menos riquezas naturales, mayor costo generará su futura obtención, si para ese momento aún resulta factible lograrla.

De otro lado, los criterios bajo los cuales prospera una organización deben estar en función del desarrollo personal de cada uno de los individuos que están involucrados en ella. Y esto no se logra creyendo po ejemplo, que la motivación de un empleado está determinada exclusivamente por la relación con su jefe o su trabajo.

Ella se encuentra definida por un conjunto mucho más amplio, en el cual también inciden aspectos como la cultura y subcultura a la que pertenece este trabajador, su círculo familiar, sus objetivos personales y la compatibilidad o incompatibilidad con los de la compañía, la estructura organizacional (su rigidez o flexibilidad), su relación con los clientes, los proveedores y con el sistema en general. Dentro del mismo, tiene un impacto importante la acción colectiva o individual, que repercute en la forma como evoluciona cada empresa.

"De esta manera también se entiende que el desarrollo, no solo implica la preocupación por el crecimiento a nivel interno, pues éste además incluye la forma en que se proyecta la participación de los proveedores dentro del sistema, la forma cómo piensan y viven los consumidores a niveles intermedios y finales, el impacto sobre la sociedad en general" (Restrepo, 2009).

...sobre el medio ambiente, y por qué no, sobre el mundo; pues día a día los procesos de globalización no sólo se refieren a un intercambio a nivel comercial. Implican además un intercambio de culturas, de ideas, de recursos naturales, tecnológicos, educativos y humanos, en fin, una integración de la especie humana que interactúa constantemente bajo diferentes clases de sistemas, donde el objetivo primordial es la sostenibilidad.
Por esta razón, cuando hablamos de ética, no sólo podemos limitarnos a crecer económicamente, sin hacerle daño al reducido espacio donde creemos habitar; se deben considerar todos los factores mencionados y muchos Paño " “étio o a ectemos negativamente, ese impacto retornará, muy posiblemente perjudicando a la oronización. Así, cuando hablemos de productividad, debemos tener presente, que no solo se debe proyectar en función de unos pocos recus de unos pocos res del sistema. Del mismo modo, sucederá con el logro de objetivos medidos por la eficacia o el mejoramiento del desempeño denotado por la eficiencia.

\section{La creación de valor en las empresas}

La base del "valor" reside en la forma como los nuevos gerentes dirigen los negocios. Ya no basta con ser un "gerente competitivo" sino que se debe experimentar una transformación a "líder"; que ante todo sabe, que "parco" y aceptar la de ser el eje central de las actividades que desarrollan todas las personas en la empresa que dirige.

"Consecuentemente, el modelo antropológico sitúa en el centro a las personas, ya no como un recurso "más", sino como seres que merecen el mejor y mayor de los respetos. Estas personas son los accionistas, los directivos, los proveedores, los empleados y los clientes. $Y$ tratarlos como personas equivale a generar un clima propicio para el logro de la más alta de las productividades que se refleja en el logro inevitable de los más altos rendimientos mercadológicos, económicos y financieros" (Méndez, 2003).

De ahí que el actuar éticamente sea una necesidad, por porque se prescriba en textos místicos, sino porque con ello estamos preparados para alcanzar éxitos financieros que conducen al crecimiento y desarrollo permanente de las empresas.

Esta actitud, del quehacer ético, está ligada al intenso desarrollo de la tecnología de la información, y a pesar de que siempre existe corrupción, fraudes y engaños, ahora es mucho más fácil detectarlos y es en la actualidad que ahora se vive, que se sabe, que más temprano que tarde, la verdad será conocida.

Tres valores que realizan las empresas son:

1. El valor económico, todos los que hicieron aportes a la actividad productiva reciben su compensación que les permitirá satisfacer sus necesidades.

2. El valor psicológico, los que participan del proceso productivo logran asimilar el aprendizaje para la toma adecuada decisiones que afectan a otros o a ellos mismos de forma directa o indirecta. 
3. El valor ético, se aduce al cambio que se produce en el interior de las personas. Los dos últimos valores son subjetivos pero su influencia es decisiva para la generación del valor económico.

El "Liderazgo Ético" es entonces una necesidad que hace mejor y más rica a la empresa. Por el contrario, si se busca el enriquecimiento acelerado y sobre bases ilícitas, la empresa se condena a sí misma. En estos tiempos, el cliente es cada día más y más exigente y más difícil de engañar; que el mundo entero se ha reducido por efecto del inmediato desarrollo de las telecomunicaciones y que el temor a una demanda por efecto de un error que afecte a terceros, es ahora muy latente en todos. Es por eso que la ética empresarial está teniendo, hoy más que nunca, una presencia determinante en la diná-
mica de las empresas modernas. Ya no es el tiempo de las glorias pasadas, alcanzadas sobre pedestales débiles o falsos. Es el momento de valorizar o revalorizar las actitudes y valores gerenciales, de tal manera que se o falsos. Es el momento de valorizar o revalorizar las actitudes y valores gerenciales, de tal manera que se
comprenda que la ética empresarial es ahora una necesidad y no una virtud. Los líderes, establecen la unidad de propósito y dirección de la organización. Ellos pueden crear y mantener el desarrollo interno en el que los

El líder, ha de tener los suficientes conocimientos técnicos, información de calidad y experiencia, para que sus acciones conduzcan al éxito. Mandar, por derecho legal, no convierte en líder. Al líder se le sigue, porque entiende, y es modelo y referente. El líder puede exigir, pero no mandar. Por imitación o deseo de agradar a líder, al que todos respetan, sus decisiones no son cuestionadas. Los liderados, son más propensos a intenta implicarse en la obtención de los objetivos. Es ejemplo y fortaleza para todo el colectivo, que se esforzará po estar a su nivel de exigencia.

Son muchas las capacidades de las que debería estar dotado un líder. En la empresa ha de ser imaginativo, diligente, esforzado. Con conocimiento de la empresa y la organización. Y ser capaz no solo de tomar decisiones acertadas, ha de saber involucrar al resto del grupo en la consecución de los objetivos, y sea acatado su mandato y dirección. El problema, era que el líder movilizaba al grupo. Pero no se sabía muy bien hacia donde. Si hacía el éxito que pocos han logrado. O hacia el desastre que es un objetivo más fácilmente alcanzable.

Debe prevalecer ante todo el bien de la humanidad y no el bien particular de una comunidad política, social o cultural. La consecución del bien común de una comunidad política no puede ir en contra del bien común de toda la humanidad, concretado éste en el reconocimiento y respeto de los Derechos del Hombre.

Las divisiones y diferencias políticas, culturales e institucionales en que se articula y organiza la humanidad son, desde esta perspectiva, legítimas en la medida en que armonicen con la pertenencia a la familia humana y con las exigencias éticas y políticas derivadas de la misma.

Habrá paz en la medida en que toda la humanidad sepa redescubrir su originaria vocación a ser una sola familia, en que la dignidad y los derechos de las personas -de cualquier estado, raza o religión- sean reconocidos como anteriores y preeminentes respecto a cualquier diferencia o especificidad. El bien de la persona humana está antes de todo y trasciende toda institución humana.

Es necesaria e improrrogable una renovación del derecho internacional y de las instituciones internacionales que tengan su punto de partida en la supremacía del bien de la humanidad y de la persona humana sobre todas participar en las decisiones, superando

Hoy en día persiste y se acrecienta la desigualdad entre un Norte del mundo, cada vez más sobrado de bienes y recursos y habitado por un número cada vez mayor de ancianos, y un Sur en el que se concentra la gran yayoría de las jóvenes generaciones, privada todavía de una persectiva esperanzadora de desarrollo social, cultural y económico.

"Desde el momento en que la humanidad llamada a ser una sola familia, todavía está dividida en dos por la pobreza -al principio del siglo XXI más de mil cuatrocientos millones de personas” (Solarte)

Viven en una situación de extrema pobreza, es especialmente urgente reconsiderar los modelos que inspiran las opciones de desarrollo.

"En el inicio del nuevo siglo, esta pobreza de miles de millones de hombres y mujeres es la cuestión que, más que cualquier otra, interpela nuestra conciencia. Cuestión aún más dramática al ser conscientes de que los mayores problemas económicos de nuestro tiempo no dependen de la falta de recursos, sino del hecho de que a las actuales estructuras económicas, sociales y culturales les cueste hacerse cargo de las exigencias de un auténtico desarrollo."

Puede que haya llegado el momento de una nueva y más profunda reflexión sobre el sentido de la economía y de sus fines.

"Parece urgente que vuelva a ser considerada la concepción misma del bienestar, de modo que no se vea dominada por una estrecha perspectiva utilitarista, que deja completamente al margen valores como el de la solidaridad y el altruismo." (Vargas, 2002).

Una economía que no considere la dimensión ética y que no procure servir al bien de la persona -de toda persona y de toda la persona- no puede llamarse a sí misma "economía" entendida en el sentido de una racional y beneficiosa gestión de la riqueza material. El único modo de hacer que la RSE esté presente en el conjunto de la gestión de las compañías es que el departamento cuente con el apoyo explícito de la alta dirección.

Más aún, deben mostrar interés activo también los órganos de gobierno y de dirección. Todos deben ser asimismo conscientes del nivel de pasivos de confianza con los que cuenta la empresa, y saber qué asuntos 
perturban la capacidad de la empresa de generar confianza o de relacionarse positivamente con los grupos de interés. Es necesario distinguir los asuntos importantes de los que no lo son, lo que implica prestar atención al entorno ca aquí y aora sin que hay que hacer prospecciones a las que se enfrenta la RSE están a medio y lino plazo,

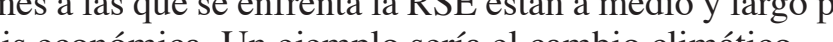

y se han desarrolado con independencia de la crisis económica. Un ejemplo sería el cambio climático.

\section{Conclusiones}

La Responsabilidad Social produce reducción de costos operativos, mejora la imagen de la marca en el mercado y logra mayor identidad y sentido de pertenencia de sus colaboradores, lo que se convierte en el mejor negocio, no con visión corta, también a futuro.

Si los profesionales, las universidades, las empresas mismas, el Estado a través de sus políticas de gobierno y así como los gremios empresariales, los académicos, los inversionistas y demás personas que de alguna form incidimos de forma directa o indirecta en el mundo empresarial no tomamos este tema con la suficiente seriedad que merece, no nos quejemos mañana cuando ya lamentaremos sea tarde.

El único modo de hacer que la RSE esté presente en el conjunto de la gestión de las compañías es que el departamento cuente con el apoyo explícito de la alta dirección. Más aún, deben mostrar interés activo también los órganos de gobierno y de dirección.

Todos deben ser asimismo conscientes del nivel de pasivos de confianza con los que cuenta la empresa, y saber qué asuntos perturban la capacidad de la empresa de generar confianza o de relacionarse positivamente con los grupos de interés.

Es necesario distinguir los asuntos importantes de los que no lo son, lo que implica prestar atención al entorno cambiante, a la vez que cuidar la calidad de las relaciones con los grupos de interés.

La reflexión no debe limitarse al aquí y ahora, sino que hay que hacer prospecciones de futuro: las preocupaciones a las que se enfrenta la RSE están a medio y largo plazo, y se han desarrollado con independencia de la crisis económica. Un ejemplo sería el cambio climático.

\section{Bibliografía}

Aguero, F. (2002). La Responsabilidad Social Empresarial en América Latina. Argentina, Brasil, Chile, Colombia, México y Perú: Cenda.

Berti, Z. G. (2008). Perfil social de la empresa en Venezuela. Venezuela: Alianza Social.

Caravedo, B. (1998). Responsabilidad Social de la Empresa, un eje para cambiar el país. Lima: SASE

Cedice, E. y. (2008). Sostenibilidad en mercados emergentes. Venezuela: Manual.

Dickson, P. P. (1993). Marketing Management. Thompson Learning.

Ferrer, F. (2009). Marketing. Pearson.

Fuentes, S. (2007), Memorias Colombia Responsable Primer Encuentro de Responsabilidad y Desarrollo Social. Bogotá: Grupo SAF. IRSE. (2009). Memoria de Responsabilidad Social Empresarial. Ekos.

Kotler, P. (2003). Los 80 Conceptos Esenciales de Marketing. Pearson.

Méndez, C. (2003). Libro de responsabilidad de empresarios y empresas en Venezuela. Caracas.

Montero, M. (2007). De la filantropía a la construcción de tejido y capital social. Venezuela: Velea.

Pizzolante. (1993). Ingeniería de la Imagen. Venezuela: Colección Ayakua.

Puterman, P. (s.f.). Guía mundial de responsabilidad social. Venezuela: International CSR.

Restrepo, R. (2009). Responsabilidad Social. Medellín: Icontec.

Schwalb, M. y. (s.f.). Responsabilidad Social. Lima.

Solarte, M. R. (s.f.). Modelo y Metodología para la gestión en responsabilidad social empresarial.

Vargas, M. (2002). Una Mirada a la inversión social en procesos de reconstrucción post-catástrofes. Venezuela.

Victor, G. (2010). La RSE: Visiones Complementarios. Alianza Social. 